\title{
Percepção sobre mercado de trabalho em enfermagem entre acadêmicos ingressantes e formandos
}

\section{Perception about nursing labor market among beginners and finalists academics}

Manoelito Ferreira Silva-Junior ${ }^{1}$, Anna Laura Martinelli², Maria Emanoelly Euzébio ${ }^{3}$, Ellen de Souza Mello ${ }^{4}$, Cristina Berger Fadel ${ }^{5}$

1. ORCID: https://orcid.org/0000-0001-8837-5912. Doutor. Universidade Estadual de Ponta Grossa, Ponta Grossa, Paraná, Brasil. E-mail: manoelito_fsjunior@ hotmail.com.

2. ORCID: https://orcid.org/0000-0002-7784-9059. Graduanda. Universidade Estadual de Ponta Grossa, Ponta Grossa, Paraná, Brasil. E-mail: annalaura.martinelli@hotmail. com.

3. ORCID: https://orcid.org/0000-0003-3090-4230. Graduanda. Universidade Estadual de Ponta Grossa, Ponta Grossa, Paraná, Brasil. E-mail: manubeliber21@gmail.com.

4. ORCID: https://orcid.org/0000-0001-8966-4193. Graduanda. Universidade Estadual de Ponta Grossa, Ponta Grossa, Paraná, Brasil. E-mail: ellenmello428@gmail.com.

5. ORCID: https://orcid.org/0000-0002-7303-5429. Doutora. Universidade Estadual de Ponta Grossa, Ponta Grossa, Paraná, Brasil. E-mail: cbfadel@gmail.com.

CONTATO: Manoelito Ferreira Silva Junior|Endereço: Departamento de Odontologia, Universidade Estadual de Ponta Grossa. Av. General Carlos Cavalcanti, 4748, Uvaranas, Ponta Grossa, Paraná, Brasil. 84030-900. Telefone: (19) 99931-5635 E-mail: manoelito_fsjunior@hotmail.com

RESUMO O objetivo do estudo foi analisar a percepção sobre o mercado de trabalho entre ingressantes e formandos do curso de Enfermagem de uma universidade pública. $O$ estudo qualitativo foi realizado com ingressantes (2019) e formandos (2018) do curso de Enfermagem da Universidade Estadual de Ponta Grossa. A amostra foi definida pelo método de saturação, a coleta de dados gravada com roteiro-guia. O material transcrito recebeu análise temática de conteúdo. Sobre o mercado de trabalho foram identificadas as categorias: mercado de trabalho amplo, mercado de trabalho saturado, mercado de trabalho exigente e mercado de trabalho desvalorizado. O mercado amplo 
deriva da percepção de diversidade no campo de atuação, porém houve sentimento de saturação, e por isto, exige experiência e maior formação profissional, tornando-o desvalorizado, principalmente no retorno financeiro. Houve uma percepção aproximada entre ingressantes e formandos sobre o mercado de trabalho em Enfermagem. Sendo assim, ao escolher o curso, o estudante tem ciência das dificuldades enfrentadas no mercado de trabalho relacionado à profissão.

DESCRITORES: Programas de Graduação em Enfermagem. Recursos Humanos em Saúde. Mercado de trabalho.

\begin{abstract}
The aim of the study was to analyze the perception of the labor market among incoming academics and graduates of the Nursing course at a public university. The qualitative study was conducted with freshmen (2019) and graduates (2018) of the Nursing course at the State University of Ponta Grossa. The sample was defined by the saturation method, the data collection recorded with a guide script. The transcribed material received thematic content analysis. On the labor market, the following categories were identified: broad labor market, saturated labor market, demanding labor market and undervalued labor market. The broad market derives from the perception of diversity in the field, but there was a feeling of saturation, which is why it requires experience and greater professional training, making it devalued, especially in terms of financial return. There was an approximate perception between new students and graduates about the job market in Nursing. Thus, when choosing the course, the student is aware of the difficulties faced in the job market related to the profession.
\end{abstract}

DESCRIPTORS: Graduate programs in nursing. Human resources in health. Labor market.

\title{
INTRODUÇÃO
}

Enfermagem no Brasil é composta majoritariamente por técnicos e auxiliares, sendo
formada apenas por $20 \%$ de enfermeiros ${ }^{1}$. Uma grande parcela dos enfermeiros
conhece o mercado de trabalho, pois um $1 / 3$ dos enfermeiros realizaram curso de auxiliar
e/ou técnico em Enfermagem previamente, e mais de $80 \%$ chegaram a atuar neste nível ${ }^{2}$.
A composição da categoria profissional em Enfermagem é bem organizada e
numerosa, e por isto, pode justificar em parte a dificuldade de inserção do mercado
para os enfermeiros quando comparados aos técnicos e auxiliares ${ }^{3}$. Além disto, segundo 
estudo publicado em 2016, os profissionais de enfermagem apresentam um grande contingente economicamente ativo, onde $91,8 \%$ estão em atividade laboral ${ }^{3}$.

A lógica de mercado privado como principal forma de ingresso no mercado de trabalho para a equipe de Enfermagem foi modificando ao longo do tempo, principalmente após a criação do Sistema Único de Saúde (SUS) ${ }^{4}$. No último levantamento de dados do Conselho Federal de Enfermagem verificou que a maioria dos profissionais estão no setor público $(59,3 \%)$, seguido pelo setor privado $(31,8 \%)$, filantrópico $(14,6 \%)$ e pelas instituições de ensino $(8,2 \%)^{1-2}$.

Os enfermeiros têm desenvolvido suas atividades laborais principalmente em hospitais (51,1\%), e em seguida nas Unidades Básicas de Saúde (UBS) $(20,1 \%)^{1-}$ 2. Neste sentido, cabe destacar a expansão da Atenção Primária à Saúde (APS) no Brasil ao longo dos últimos anos, uma vez que a APS é a porta de entrada principal e centro coordenador e de comunicação com toda a Rede de Atenção à Saúde ${ }^{5}$. A Estratégia Saúde da Família (ESF), como forma de reorientação da APS no Brasil, se tornou o principal pilar de descentralização e expansão do mercado de trabalho da enfermagem, pois contribui na mudança do foco da assistência hospitalar para ambulatorial, domiciliar e comunitária ${ }^{2,5}$.

É inegável que o setor público é um mercado significado e diferenciado para o enfermeiro, onde a saúde torna-se uma produção de bens e serviços em uma máxima de produção social, diferente do universo mercadológico até então vivenciado no universo do setor privado². Neste sentido, o processo de formação do enfermeiro deve estar alinhado e adaptado as mudanças ocorridas no mercado de trabalho, sem privilegiar apenas a inserção ou permanência do profissional, mas com a capacidade de responder às transformações ao longo do tempo 6 .9.

No intuito de formar profissionais críticos, reflexivos, éticos e políticos, impulsionando a profissão e formando enfermeiros com maior inserção e participação social, os cursos de graduação em Enfermagem vêm sofrendo sucessivas mudanças curriculares para atender às exigências de produtividade e qualidade do mercado de trabalho e às necessidades de saúde da população em uma perspectiva humanista ${ }^{6-7,9}$. No entanto, pouco se sabe sobre a percepção de acadêmicos de Enfermagem sobre o conhecimento e intencionalidade no mercado de trabalho.

A maioria dos estudos presentes na literatura abordam a temática de forma quantitativa ${ }^{10-11}$, e apesar de ter aumentado o uso de abordagem qualitativa ${ }^{8,12-13}$, tem foco apenas nos egressos $8,10-12,14$. Nesse sentido, o presente estudo tem por objetivo analisar a percepção sobre o mercado de trabalho entre ingressantes e formandos do curso de Enfermagem de uma universidade pública. 


\section{MÉTODO}

\section{Desenho e local do estudo}

Foi realizado um estudo qualitativo com ingressantes (2019) e formandos (2018) do curso de Enfermagem da Universidade Estadual de Ponta Grossa (UEPG), Ponta Grossa-PR, Brasil.

O curso de Enfermagem da instituição foi aprovado no ano de 2006, com duração inicial de 4 (quatro) anos para a formação acadêmica. No ano de 2014 o referido curso teve aprovado novo Projeto Político Pedagógico do Curso (PPC), o qual alterou a vigência do curso para 5 (cinco) anos, em tempo integral. O presente estudo foi realizado com a primeira turma do novo PPC.

\section{Amostra}

O tamanho amostral foi realizado pelo método da saturação entre o universo de 40 ingressantes em 2019 e 20 formandos em 2018 do curso de Enfermagem da UEPG.

Dentre os critérios de elegibilidade, entre os ingressantes foi estar matriculado no primeiro ano no primeiro semestre letivo em 2019 e entre os formandos estar matriculado no último ano do curso no segundo semestre letivo de 2018 e concordar em assinar o Termo de Consentimento Livre e Esclarecido (TCLE). Os critérios de exclusão foram alunos do primeiro ano que não ingressaram no ano de 2019 por possuir dependência ou trancamento do curso, e alunos do último ano que não integralizaram todas as disciplinas ou apresentaram condição de dependência.

\section{Coleta de dados}

A coleta de dados para os ingressantes foi realizada no primeiro mês letivo do ano de 2019, e dos formandos foi realizada durante o último mês de aulas do curso em 2018. A abordagem foi individual, na própria instituição, em local reservado.

A coleta de dados foi realizada através de entrevistas por roteiros-guia registradas por dois entrevistadores simultaneamente, sendo um pesquisador destinado aos ingressantes e o outro aos formandos, utilizando um gravador de voz digital (Sony ICDPX312, Estados Unidos). O roteiro-guia foi desenvolvido pelos pesquisadores e houve a realização com acadêmicos de outra instituição de ensino.

Para o presente estudo foram utilizadas as mesmas questões-norteadoras para os acadêmicos, ingressantes e formandos, a saber: 'O que você acha sobre o mercado de trabalho atual para o seu curso? E para o recém-formado?' e 'Relate qual sua expectativa para inserção no mercado de trabalho imediatamente após a conclusão do seu curso de graduação? E após dois anos de formado?'. 


\section{Análise dos dados}

O material produzido por meio das questões norteadoras das entrevistas após transcritos na íntegra foi tratado de acordo com a técnica da Análise Temática de Conteúdo ${ }^{15}$.

A análise dos dados foi realizada por dois pesquisadores independentes para os ingressantes, e dois pesquisadores para os formandos. Após a categorização individual, houve o consenso entre os pesquisadores envolvidos por grupo, ingressante e formando, e por último, houve o agrupamento entre as categorias dos grupos: ingressantes e formandos.

A ordenação dos achados permitiu uma abordagem descritiva do material empírico, a qual, visando à confidencialidade dos sujeitos foi codificada como ingressantes (I) e formandos $(F)$.

\section{Aspectos éticos}

O estudo foi aprovado pelo Comitê de Ética em Pesquisa da Universidade Estadual de Ponta Grossa, sob o número 3.019.438. Os sujeitos participantes maiores de 18 anos assinaram um Termo de Consentimento Livre e Esclarecido (TCLE), e os menores de 18 anos, além da assinatura do TCLE pelo responsável, também assinaram um Termo de Assentimento Livre e Esclarecido (TALE).

\section{RESULTADOS}

Participaram do estudo 16 ingressantes e 9 formandos do Curso de Enfermagem da UEPG. O tempo de entrevista variou entre 6 e 17 minutos.

A maioria dos ingressantes e a totalidade dos formandos eram mulheres, com médias etárias de 17 e 23 anos, respectivamente. A renda familiar entre ingressantes foi de 3 a 4 salários e para os formandos de 1 a 2 salários. A forma de ingresso principal na instituição por ambos os grupos foi por meio de vestibular e vagas universais (Quadro 1).

Quadro 1. Características da amostra. Ponta Grossa-PR, Brasil, 2018-2019.

\begin{tabular}{|c|c|c|c|c|c|}
\hline $\begin{array}{c}\text { Participante } \\
\text { (Código) }\end{array}$ & Sexo* & $\begin{array}{c}\text { Idade } \\
\text { (anos) }\end{array}$ & $\begin{array}{c}\text { Forma de } \\
\text { ingresso }\end{array}$ & $\begin{array}{c}\text { Renda familiar } \\
\text { (Salário Mínimo) }\end{array}$ & $\begin{array}{c}\text { Ingresso } \\
\text { por co- } \\
\text { tas }\end{array}$ \\
\hline I1 & $\mathrm{M}$ & 18 & Vestibular & 5 a 6 & Sim \\
\hline I2 & $\mathrm{H}$ & 18 & Vestibular & 3 a 4 & Não \\
\hline I3 & $\mathrm{M}$ & 18 & Vestibular & 3 a 4 & Sim \\
\hline I4 & $\mathrm{M}$ & 17 & Processo Seletivo Seriado & 3 a 4 & Não \\
\hline I5 & $\mathrm{H}$ & 17 & Vestibular & 3 a 4 & Não \\
\hline I6 & $\mathrm{H}$ & 19 & Vestibular & 3 a 4 & Não \\
\hline I7 & $\mathrm{M}$ & 18 & Vestibular & 5 a 6 & Sim \\
\hline I8 & $\mathrm{H}$ & 18 & Vestibular & 3 a 4 & Não \\
\hline
\end{tabular}




\begin{tabular}{|c|c|c|c|c|c|}
\hline 19 & $M$ & 17 & Vestibular & 5 a 6 & Sim \\
\hline $\mathbf{I 1 0}$ & $\mathrm{M}$ & 18 & Processo Seletivo Seriado & 3 a 4 & Não \\
\hline $\mid 11$ & $M$ & 18 & Processo Seletivo Seriado & 3 a 4 & Não \\
\hline $\mathbf{I 1 2}$ & $\mathrm{M}$ & 18 & Vestibular & 3 a 4 & Não \\
\hline I13 & $\mathrm{M}$ & 17 & Vestibular & 5 a 6 & Não \\
\hline I14 & $\mathrm{M}$ & 17 & Processo Seletivo Seriado & 1 a 2 & Não \\
\hline $\mathbf{I 1 5}$ & $\mathrm{M}$ & 20 & Vestibular & 1 a 2 & Sim \\
\hline $\mathbf{I 1 6}$ & $\mathrm{M}$ & 18 & Vestibular & 3 a 4 & Sim \\
\hline $\mathrm{F} 1$ & $\mathrm{M}$ & 22 & Vestibular & 1 a 2 & Não \\
\hline $\mathbf{F 2}$ & $\mathrm{M}$ & 22 & Processo Seletivo Seriado & 1 a 2 & Sim \\
\hline F3 & $\mathrm{M}$ & 22 & Vestibular & 1 a 2 & Não \\
\hline F4 & $\mathrm{M}$ & 24 & Vestibular & 5 a 6 & Não \\
\hline F5 & $\mathrm{M}$ & 23 & Vestibular & +8 & Sim \\
\hline F6 & $\mathrm{M}$ & 21 & Processo Seletivo Seriado & 1 a 2 & Sim \\
\hline F7 & $\mathrm{M}$ & 23 & Vestibular & 5 a 6 & Não \\
\hline F8 & $\mathrm{M}$ & 23 & Transferência & 1 a 2 & Não \\
\hline F9 & M & 23 & Vestibular & 1 a 2 & Sim \\
\hline
\end{tabular}

${ }^{*} \mathrm{M}=$ Mulher e $\mathrm{H}=$ Homem.

Em relação ao tema mercado de trabalho foram identificadas as seguintes categorias de análise: mercado de trabalho amplo, mercado de trabalho saturado, mercado de trabalho exigente e mercado de trabalho desvalorizado.

\section{Mercado de trabalho amplo}

A percepção do mercado de trabalho como amplo derivou nas falas que seguem, e fez menção à vasta área de atuação do enfermeiro:

Eu acho que é bem amplo porque tem bastante áreas que a gente pode atuar... (Ingressante 7)

Então, eu acho que é uma profissão que sempre tem emprego, não importa, por ter muitas áreas né, eu acho que alguma forma a gente consegue... (Ingressante 6)

Por sempre ter essa alta demanda do pessoal, de pessoas precisando de um cuidado específico, tratamento, eu vejo que tem bastante oportunidade sabe... Tem mercado. (Ingressante 2)

Eu acho que é muito amplo. A gente consegue se adaptar a situações que... A gente teve, assim, experiências, né?, com pessoas que se formaram que a gente falava 'Nossa, não sabia que podia atuar nisso'. Acho que é bastante amplo, assim. (Formando 2)

E ainda, há uma atenção que inclui vários ciclos de vida para poder atual, como descrito:

Ah, eu acho que é muito bom. Porque... Têm várias áreas de atuação. 'Cê' pode trabalhar... Desde criança, até idoso.... (Formando 1) 
Além disso, houve entre os entrevistados o sentimento da existência de um mercado de trabalho no serviço público pouco explorado:

Pois então. Aqui na cidade, que... A gente pôde presenciar, assim, na... Nesses últimos estágios, é que... A... A saúde pública na prefeitura tá bem carente de enfermeiro. Tanto que abriu um concurso, e agora acho que acredito que vão chamar, e espero que chamem porque... Tá precisando muito, muito mesmo. E assim, eu nunca... Nunca fui ver em hospitais, nem nada, assim. Mas eu acho que tá bem carente do... Da enfermagem, então vai ser um mercado que é capaz de aceitar todo mundo, né. Em algum lugar sempre vai ter lugar. (Formando 5)

\section{Mercado de trabalho saturado}

Ao mesmo tempo que os acadêmicos apontaram o mercado de trabalho de Enfermagem como amplo, houve a percepção de saturação, com a menção sobre as diferenças regionais na distribuição dos profissionais e à disseminação do curso.

É muito dependendo da região, porque tem região que tem muito mais oferta de trabalho que outras... (Ingressante 5)

Eu acho que tá um pouco complicado, porque normalmente as pessoas tem escolhido muito fazer Enfermagem. (Ingressante 15)

Quando as relações de oferta e procura por emprego são desequilibradas, podem existir medidas que facilitam ou dificultam a inserção no mercado para os recémformados, e uma delas foi a questão de indicação profissional, como citada abaixo:

Puxadinho, né? Eu fico mais tranquila porque eu tenho conhecido já, que trabalha no regional como enfermeiro... Mas eu acho que se dependesse só de mim, eu ia sofrer mais pra conseguir alguma coisa. (Ingressante 10)

Assim, no começo, quando eu... Eu entrei, todo mundo falava assim "Ai, porque a enfermagem você nunca vai tá desempregado, você sempre vai ter um emprego" e isso e aquilo... Só que eu vejo que hoje em dia, realmente tem emprego, só que é muito por indicação. Por exemplo, tem... Eu tenho, vou citar né um exemplo que a minha amiga ela se formou aqui na UEPG mesmo, e... Ela ficou dois anos mandando currículo em todos os hospitais aqui de, de Ponta Grossa e não conseguiu emprego. Agora que ela foi conseguir, depois de dois anos. Então eu vejo assim que é muito indicação. "Ah, um enfermeiro, ah, aquela ali se formou mas ela é uma aluna boa", ou... "Ah, eu conheço tal". E eles também não dão op... Não tão dando oportunidade pra quem não tem experiência. Por exemplo, tem um anúncio de um emprego pra enfermeiro logo eles... (Formando 8)

\section{Mercado de trabalho exigente}

Apesar de entender que o mercado é amplo, os acadêmicos percebem que aspectos individuais podem auxiliar a facilidade para entrar no mercado de trabalho, que vai exigir mais entre os proponentes à uma vaga, como descrito:

É meio que uma seleção natural assim, não tem muito o que fazer, se você for bom, dedicado vai aparecer numa hora ou outra... (Ingressante 9) 
Se o profissional for, né? Coerente, honesto, eu acho que... É um mercado de trabalho bem bom. (Formando 2)

E ainda, o mercado tem pedido cada vez uma formação adicional para diferenciar os profissionais, e a formação continuada, tem sido um meio muito relatado pelos acadêmicos, como apontado pelos participantes do estudo:

...Eu acho que é um mercado muito amplo... eu acho que se você é um profissional capacitado e estudou muito sabe? Você vai conseguir. (Ingressante 12)

Os veteranos também já comentaram da parte do quinto ano tipo, que geralmente não falta emprego, tipo especialmente se você começa, não faz só a graduação, tipo estuda mais que isso. (Ingressante 8)

É que na residência (...) ao mesmo tempo em que você tá... Ali se especializando, você tá também pegando... É... "Treinando", digamos assim. É... Digamos assim, que você tem mais... Pega experiência, né, que é mais difícil. Quando você entra direto no mercado de trabalho, você não tem experiência alguma. Já é difícil por isso, sem experiência não te pegam. Então, com a residência, eu adquiriria a... A especialização e a experiência que eu precisava. Pra entrar. (Formando 6)

A gente já sai recém-formado, não tem muito conhecimento, já tem um preconceito porque querendo ou não se você é paciente 'cê' vai chegar lá 'cê' vai querer ser atendido por um profissional que tem mais experiência, não um recém-formado. Então, acredito que dificulta, assim, um pouco. Por isso que eu acho importante fazer né, uma pós [graduação], um mestrado, alguma coisa. (Formando1)

Outro ponto bem recorrente sobre a exigência do mercado tratou-se das experiências profissionais. Este item foi bem relatado principalmente entre os formandos, como nos discursos:

Ah, pro recém-formado é mais difícil (risos). Até porque... Quando, acredito né, que quando chamam por currículo assim, que... Precisa ter algum mínimo de experiência. (Formando 1)

É [(difícil inserção no mercado de trabalho para o recém-formado) (...). Pela falta de experiência. Normalmente, essa vaga que eu tentei... É... Dentro dessa vaga que eu tentei, eles exigiam a... A questão da experiência, né. Mas daí eu... Até que eu vou entrar naquele processo do "trainee", sabe, que são, hã... Profissionais que não tem a... A experiência, e eles meio que "treinam" pra daí... Entrar mesmo no... No mercado de trabalho. Então, até nessa questão, o salário é menor porque eu não tenho experiência. (Formando 6)

Eles cobram bastante essa questão da experiência, né? É... Isso eu acho que não é só da Enfermagem, só da nossa profissão, é em qualquer profissão, eles... Vão querer um diferencial, isso é óbvio, né. Tem pessoa que conseguiu, ali, um estágio, conseguiu uma experiência, ela vai tá, com certeza, um pouco à frente aí no mercado de trabalho. Mas não que isso seja... Eu acho assim, que não... Não que seja ruim. Eu, eu acho assim que por mais que a gente não tivesse passado na residência a gente teria oportunidade. (Formando 2) 


\section{Mercado de trabalho desvalorizado}

Entre os participantes do estudo ficou claro o sentimento de uma profissão onde os profissionais conseguem se inserir no mercado de trabalho, no entanto, sem o merecido reconhecimento:

Eu acho que assim, a maioria dos enfermeiros consegue entrar no mercado de trabalho, porém, não são bem valorizados né...E isso me entristece... (I3)

Eu acho que é muito desvalorizado... eu já vi que a gente aprende muita coisa e eles deveriam dar mais valorização pro nosso... pra profissão né... (I1)

Inclusive, o sentido da desvalorização em grande parte foi associado pelos participantes do estudo à questão de retorno financeiro, como nos discursos:

Eu acho que é uma profissão que tem muita área, só que eu acho que não é tão remunerado quanto deveria ser... (Ingressante 13)

Acho muito desvalorizado porque a gente sempre vê... Ganha muito pouco, muita hora trabalhada... (Ingressante 4)

Geralmente o enfermeiro trabalha muito e recebe pouco, né? (Ingressante 11)

Pouco valorizado, aqui no Paraná principalmente...eu pude ver essa realidade na diferença de trabalho, na desigualdade de pagamento sabe? (Ingressante 16)

Cidade pequena como aqui. Então... É... A questão da valorização da Enfermagem também, dá uma diferença de salário bem grande. Então em Irati, vou ganhar menos do que eu ganharia aqui, em Ponta Grossa, por exemplo. Então isso... Varia muito. Isso eu... vi, assim (risos) claramente quando eu fui... (Formando 6)

Os problemas enfrentados pela classe profissional de modo geral, parece ainda ser mais difícil para o recém-formado, como na fala:

Olha, já ouvi relatos de que recém-formado em algumas instituições é... Ganha menos, mas é questão de experiência mesmo. Acho que em qualquer lugar, a gente sempre entra como, é... Aprendiz. Claro que o nosso salário não vai ser igual ao... À pessoa que tá lá há vinte anos. Mas... Tem que tudo ter um, né? Na verdade, é mais a pessoa que trabalha junto com você se ela tem preconceito ou não, se ela 'tá disposta a te ajudar ou não, vai querer ser esse... Mas eu acho que não tem assim uma dificuldade. (Formando 5)

\section{DISCUSSÃO}

A feminilização da profissão da Enfermagem é bem estabelecida pela literatura, onde mais de $80 \%$ dos profissionais no mercado são mulheres ${ }^{1-2,16-17}$. Além disto, a idade média entre os ingressantes e formandos de Enfermagem foi parecida com a literatura ${ }^{2}$, com diferença de um ano maior para a presente amostra, o que pode ser justificado pela duração do curso ser de cinco e não de quatro anos. 
A baixa renda familiar entre estudantes de Enfermagem tem sido demonstrada em outros estudos, inclusive também relacionada a uma baixa escolaridade dos pais, mesmo entre estudantes de faculdades particulares ${ }^{16-17}$. Se por um lado há a efetivação das políticas indutoras de inclusão social nas universidades, por outro lado, pode revelar as desigualdades sociais inerentes às escolhas profissionais, atrelada não apenas ao desejo pessoal, mas talvez associada à sua maior chance de conseguir alcançar uma vaga no ensino superior. Este aspecto pode denotar que pessoas oriundas de níveis socioeconômicos mais elevados tendem a ingressar em cursos com maior prestígio social e denotar um processo de desigualdade na democratização do ensino superior ${ }^{18}$.

Assim como no presente estudo ficou claro que os participantes perceberam o mercado para o enfermeiro como amplo, um estudo mostrou que esta escolha profissional foi bem aceita pelos familiares, principalmente por observarem que a área da Enfermagem dispõe de um leque com vários caminhos a seguir ${ }^{19}$. Mas os desafios da escolha profissional servem de subsídio para investigar a identidade profissional do enfermeiro sob outra ótica ${ }^{19}$. Neste sentido, deve-se reforçar sobre a baixa renda dos familiares destes estudantes, como apontado no presente estudo e na literatura ${ }^{16-17}$, onde a oportunidade de um curso superior na área da saúde pelos seus filhos, aspecto não vivenciado por eles, seja suficiente para uma carreira profissional melhor do que as suas próprias.

A Enfermagem é uma das poucas profissões na qual o mercado de trabalho continua em expansão ${ }^{2}$. Ao contrário do que tem acontecido com a redução da mão de obra intensiva no setor de serviços derivadas da era tecnológica, o setor saúde tem ainda crescimento expressivo nas últimas décadas ${ }^{4}$.

No setor de saúde, a Enfermagem apresenta o maior contingente de trabalhadores, representado por cerca de $50 \%$ da força de trabalho, considerando técnicos, auxiliares e enfermeiros. Nesse sentido, a participação da Enfermagem é imprescindível na consecução das metas institucionais, tanto no setor público como no privado ${ }^{4}$. O mercado de trabalho para a Enfermagem cresce a cada dia e diversifica-se cada vez mais. Essa ampliação dos campos de atuação deve-se ao reconhecimento do profissional e ao seu preparo para atuar em diversas áreas da saúde ${ }^{4}$. Nesse sentido, a Resolução $n^{\circ} 389$, de 18 de outubro de 2011 , retrata essa diversidade pela grande quantidade de registros de títulos de pós-graduação lato e stricto sensu concedido a enfermeiros ${ }^{19}$.

Sem dúvidas, a diversidade de áreas de atuação na Enfermagem amplia a oportunidade e a empregabilidade. As áreas de atuação da Enfermagem são inúmeras, no que pese as atividades de prevenção, promoção, proteção e reabilitação da saúde a todos os ciclos de vida, desde campanhas educativas e de vacinação até atendimento ambulatorial e de domicílio, no tratamento de doentes. Estes espaços configuram-se como abrangentes $o$ suficiente para oportunizar a colocação dos profissionais no mercado de trabalho. Esta 
gama de possibilidades é um dos principais atrativos para que os cursos de Enfermagem tenham grande demanda ${ }^{4,10}$.

Deixa-se claro que os países em desenvolvimento, com transição demográfica tardia, como o Brasil, onde ainda há alta taxa de natalidade e base populacional com tendência de envelhecimento, existe uma ampla dispersão de cuidados de saúde em diferentes estratégias por ciclo de vida ${ }^{20}$.

Após a implantação do SUS, principalmente após os anos 90, os postos de trabalho em saúde aumentaram expressivamente, e por isso, tronou-se um mercado de trabalho atraente para os enfermeiros ${ }^{5}$, fato esse constatado pelo número de concursos abertos no país ${ }^{4}$. No entanto, apesar da expansão dos serviços públicos de saúde no Brasil, sabe-se que ainda não há cobertura total de saúde para população e existe um mercado amplo a ser explorado, assim como constatado pela formanda.

O Brasil apresenta média de 0,6 enfermeiros para cada 1.000 pessoas, estando muito abaixo da relação de 5 a 10 enfermeiros por 1000 habitantes nos países europeus ${ }^{14}$. Para tentar minimizar o problema, houve uma expansão de vagas nos cursos de Enfermagem, porém o crescimento do número de vagas é insuficiente para atender às múltiplas e variadas demandas da atenção à saúde da população nos níveis local, regional e nacional ${ }^{14}$, principalmente considerando as desigualdades regionais na distribuição das Instituições de Ensino Superior (IES) e das vagas. Este aspecto pode influenciar a percepção dos entrevistados, como será discutido abaixo na segunda categoria de análise.

A percepção de saturação do mercado de trabalho foi também apontada por estudantes e profissionais em diversos estudos ${ }^{10,12-14}$. Um estudo apontou que há uma predominância de enfermeiros residentes em grandes centros urbanos, principalmente nas capitais, e principalmente na região Sul e Sudeste ${ }^{2,14}$.

Neste sentido, ao tentar inserir-se no mercado de trabalho em locais com maior desenvolvimento social, não há como não se constatar uma maior competitividade e menor empregabilidade, e por isso, a saturação é um dos principais motivos para dificuldade apontada pelos egressos na inserção no mercado de trabalho ${ }^{10,12-14}$. Além de outros fatores complicadores, tais como: o aumento considerável nos últimos anos do número de Instituições de Ensino Superior, cursos ou vagas em Enfermagem, logo de mais egressos da graduação em Enfermagem, como também uma redução da oferta de vagas pelas instituições empregadoras ${ }^{13}$.

Nos anos 80, houve um aumento descontrolado de faculdades de Enfermagem, desconsiderando as necessidades regionais, além de uma grande diversidade de currículos entre os cursos ${ }^{14}$. Nos anos 90 houve uma melhoria no sistema educacional, no entanto, houve expansão majoritária de cursos e vagas ocorreu principalmente no setor privado ${ }^{14}$. Entre os 
anos de 2000 a 2007 houve um aumento de mais de $300 \%$ de novos cursos superiores de Enfermagem no Brasil, sendo que a maioria destes estão concentrados na região Sul e Sudeste (63\%), ou seja, nas regiões mais desenvolvidas economicamente do país ${ }^{14}$.

O desemprego, atrelado a saturação do mercado e estagnação econômica atual, é uma realidade no campo da Enfermagem ${ }^{3,13}$. No Brasil, existem hoje 560 mil enfermeiros, sendo mais de 27 mil no estado do Paraná1, local de realização do presente estudo. A Enfermagem mostra problemas de empregabilidade ${ }^{2}$, inclusive com migração e aumento significativo do número de enfermeiros que trabalham fora da sua área de sua formação ${ }^{13}$, ou ainda, em atividades autônomas, tais como assistência domiciliar².

Neste sentido, a percepção sobre o mercado de trabalho entre os participantes desta amostra pode ser entendida, visto que o município que abriga a IES em análise está entre os cinco mais populosos do estado do Paraná e conta atualmente com quatro cursos de graduação em Enfermagem. Sendo assim, o sentimento de saturação é legítimo, pois há um aumento descontrolado e centralizado de cursos de graduação no país, formando um grande número de profissionais no mercado e aumentando a competição. Ao considerar estes fatores limitantes, deve-se destacar medidas importantes a serem adotadas pelos enfermeiros egressos, principalmente no intuito de se inserir em municípios do interior de menor porte e/ou em regiões como Centro-Oeste, Norte e Nordeste.

As principais formas de ingresso nos empregos em Enfermagem são derivadas de processo seletivo, concurso público e indicação de colegas ${ }^{8,10}$. No entanto, como mostra o uso do critério de indicação profissional como uma segurança entre uma entrevistada ingressante, o uso do método de indicação a uma vaga como devem ser pensada em longo prazo, pois implica diretamente na qualidade da força de trabalho disponível ${ }^{13}$. Tem-se visto principalmente no setor privado, mas também nos processos seletivos no setor público, uma prática de inserção no mercado de trabalho sem critérios de igualdade e/ou direitos de seleção por mérito ${ }^{13}$, e por isso, dependente de aspectos como currículo, concursos, oportunidades, indicações e sorte ${ }^{8}$. Entre egressos de Enfermagem de um curso público do Sul do Brasil, a maioria conseguiu o primeiro emprego por meio de processo seletivo, e por isso, o egresso precisa possuir uma boa rede de relacionamentos interpessoais a fim de facilitar o seu ingresso no mercado de trabalho ${ }^{8}$.

O mercado de trabalho com maior número de profissionais disponíveis e ausência de postos de trabalho para este contingente, tem deixado o mercado mais competitivo, logo, mais seletivo e exigente ${ }^{13}$. Além disso, as exigências e as consequentes mudanças no mercado de trabalho para Enfermagem são atribuídas à própria dinâmica do setor saúde, que vem associada a uma rede de determinantes políticos e econômicos ${ }^{4,6,9}$.

Nesse sentido, os acadêmicos pontuaram outros quesitos no âmbito pessoal que são necessários para facilitar a inserção ou manutenção do enfermeiro no mercado de 
trabalho. Um estudo quantitativo com enfermeiros egressos de uma instituição pública apontou existir características pessoais que facilitam o ingresso no mercado de trabalho, tais como: ter iniciativa, interesse, persistência e preparar-se e ter bom desempenho nos processos seletivos e apresentar bom desempenho nos processos seletivos ${ }^{10}$. Apesar destes elementos aparecem no âmbito individual, eles podem e devem ser reforçados durante a sua formação profissional.

O mercado de trabalho apresenta exigências crescentes de produtividade, mas também de qualidade, com implantação de modelos de formação e de gestão da força do exercício profissional baseados em competências profissionais que vão além do aspecto técnico-instrumental, mas também como intelectual ${ }^{14}$, e para isto, a educação deve estar para além da capacidade de se realizar tarefas, mas de planejá-las. Neste contexto, as demandas de uma sociedade complexa consistem em um grande desafio para os educadores que tem como função formar profissionais aptos a responderem corretamente as necessidades de um mercado de trabalho cada vez mais competitivo ${ }^{7-8}$.

A crescente variedade de funções e atribuições do enfermeiro no processo de trabalho tem exigido cada vez mais um profissional que consiga responder às exigências para uma melhora da qualidade da assistência, e isso, inclui, por exemplo, a necessidade de melhoria no processo formativo ${ }^{21}$.

Apesar da graduação em Enfermagem cumprir seu papel formativo, ainda há entre os formandos um sentimento da necessidade de busca pela formação educação continuada, principalmente capacitações e especializações, como forma de diferenciação no mercado de trabalho ${ }^{12,14}$. Este aspecto se confirma, quando diversos estudos mostram que a falta de especialização é um fator complicador para enfermeiros na inserção no mercado de trabalho ${ }^{10,12}$.

É evidente que a educação continuada e educação permanente são fundamentais para que o profissional assuma uma postura crítica, reflexiva e com responsabilidade na construção e aprimoramento dos seus saberes ${ }^{8,12}$. No entanto, a pós-graduação não pode ser pensada enquanto uma forma de compensar as deficiências encontradas na graduação ou ainda apenas como forma de complementar o currículo enquanto exigências do mercado de trabalho, mas realmente ser uma forma de crescimento pessoal e profissional.

Um dos papéis da universidade é fomentar possibilidades, através do ensino, pesquisa e extensão, do aprender a aprender ${ }^{10}$. As atividades extracurriculares e aprimoramento multiprofissional têm sido uma forma importante de ingresso e permanência no mercado de trabalho da área da Enfermagem, como também uma oportunidade do acadêmico ser sujeitos na construção do seu próprio conhecimento. Logo, não cabe apenas exigir o ensino que espera, mas também se motivar na busca pelos recursos/possibilidades de aprendizado disponíveis ${ }^{10}$. 
A falta de experiência profissional é um fator bem exigido na contratação profissional na grande maioria das instituições privadas. Em ambientes hospitalares a falta de profissionais qualificados para o exercício das funções mantém inúmeras vagas não preenchidas, mesmo havendo enfermeiro disponível, porém sem experiência ${ }^{8}$ e este aspecto se torna ainda mais complexo para os enfermeiros os recém-formados ${ }^{13}$.

Mas como resolver a questão da ausência de referências profissionais no currículo entre recém-formados, em um curso na maioria das vezes de forma integral, onde há carga-horária extensa referente à parte clínica e internatos no PPC. Estão questão é uma via de mão dupla, uma vez que a falta de oportunidade gera a falta de experiência, e a pouca experiência reduz a oportunidade. Neste sentido, cada vez mais, a inserção de egressos se torna difícil, e por isto, a pós-graduação pode se tornar um caminho, principalmente por meio dos programas de residência, cada vez mais popularizado no campo de saúde ${ }^{11}$.

As experiências profissionais ocorrem por meio de novos desafios e oportunidade durante a vivência prática conforme a necessidade de cada situação. Não há um único, caminho, e por isso, cabe ao sujeito inserir-se no processo educativo, agindo com consciência crítica-reflexiva, a fim de questionar a prática implementada, buscando sanar as suas dúvidas por meio da investigação e integração dos seus conhecimentos teóricos com a prática ${ }^{6,8-9}$.

Assim como descrito pelos participantes do presente estudo em relação à desvalorização da profissão, um estudo apontou as condições de trabalho dos enfermeiros como não favoráveis e dignas ${ }^{3}$, ou seja, apesar de conseguirem se inserir, não apresentam satisfação profissional como se esperava. Este aspecto explica-se em parte pelo efeito da saturação, pois o empregador entende existir uma fila de espera, oferta emprego com contratação de enfermeiros por tempo determinado, com tendência a redução dos direitos trabalhistas, ausência de segurança laboral e impactos diversos na remuneração ${ }^{17}$.

Apesar do prestígio social de uma profissão estar relacionado à valorização da categoria profissional frente à sociedade, a Enfermagem tem muita dificuldade em explicar a definição da sua função, o que influencia os conceitos de autonomia da profissão, $0^{4,22}$. A Enfermagem, por se tratar de uma profissão com especificidades de cuidar do outro e doar parte de sua vida ao trabalho, deveria ter salários dignos e compatíveis com a carga horária, mas isso não é realidade, acarretando em profissionais descontentes ${ }^{2} \mathrm{e}$ sem uma valorização profissional condizente com o seu papel social.

Os enfermeiros também manifestaram expectativas quanto à definição de papeis específicos e função profissional: desejam autonomia e identidade profissional, aspiração de serem reconhecidos pelo que realmente são. Neste contexto, a Enfermagem precisa 
ocupar espaços e ter o reconhecimento enquanto uma das profissões essenciais da saúde. Necessita de uma agenda política específica que expresse os vários aspectos constitutivos de uma profissão, isto é, o saber específico, o mercado de trabalho, a forma de organização, que apontem sobre a necessidade de cada categoria participar mais efetivamente das diferentes iniciativas que dizem respeito à saúde, no sentido de ampliar a visibilidade do saber e do fazer em Enfermagem ${ }^{4,22}$.

Observou-se que o salário foi um fator limitante para a busca de um emprego como enfermeiros, e ainda, a existência de auxiliares e técnicos de enfermagem considerando seu tempo de trabalho, com salario melhor do que enfermeiros recémformados ${ }^{14}$. Um estudo mostrou uma renda media para o recém-formado de 4,5 salários mínimos, por até 44 horas semanais de trabalho ${ }^{11}$. No entanto, há uma grande variação salarial de lugar para lugar, além da excessiva carga-horária de trabalho, e em relação às responsabilidades profissionais inerentes ao trabalho do enfermeiro.

Conforme apontado pelo participante, um estudo apontou que apesar de a maioria dos participantes estar empregada, houve relato de dificuldades para o ingresso no mercado de trabalho ${ }^{23}$, com tempo para ingresso do recém-formado entre 6 a 12 meses após a formatura, sendo maior na área assistencial ${ }^{10,11}$, sendo as dificuldades do primeiro emprego relacionadas a falta de experiência prévia, a saturação do mercado de trabalho em regiões como o Sudeste ou até mesmo a incompatibilidade com o perfil exigido pelo empregador ${ }^{11}$.

\section{CONSIDERAÇÕES FINAIS}

Apesar dos acadêmicos investigados enxergarem a área da Enfermagem com um mercado de trabalho amplo, decorrente das diversas possibilidades de atividades a serem desenvolvidas no campo de atuação, apresentam o sentimento de um mercado de trabalho saturado. Neste sentido, o local de formação, ou seja, estudarem em um município de grande porte localizado no interior do Paraná parece ter influenciado na sua percepção quanto ao mercado de trabalho, uma vez que estão alocados na região do país com grande quantidade de Instituições de Ensino, cursos e vagas ofertadas, logo, uma importante concentração de enfermeiros.

Ao considerar o mercado de trabalho competitivo, há alusão também de um mercado exigente, principalmente em relação à necessidade de melhor experiência profissional e um maior nível formativo, valorizando especialmente as residências como modo de pósgraduação. Ao entender a necessidade de uma maior qualificação profissional para obter sucesso na profissão, entendem que o a profissão torna-se desvalorizada, principalmente em relação ao retorno financeiro. 
Houve uma percepção aproximada entre os ingressantes e formandos de Enfermagem sobre o mercado de trabalho, embora os formandos tenham informações mais críticas em relação ao ingresso de recém-formados, provavelmente pela maior proximidade com o objeto de estudo. Sendo assim, parece que ao escolher o curso de Enfermagem, o estudante já tem em parte, ciência das dificuldades a serem enfrentadas no mercado de trabalho relacionado à profissão.

\section{REFERÊNCIAS}

1. Machado $\mathrm{MH}$, Aguiar-Filho W, Lacerda WF, Oliveira $\mathrm{E}$, Lemos W, Wermelinger M, et al. Relatório final da Pesquisa Perfil da Enfermagem no Brasil (Convênio: Fiocruz/Cofen). Rio de Janeiro: 28 volumes, NERHUS-DAPS-Ensp/Fiocruz e Cofen; 2015. Disponível em: http://www.cofen.gov.br/perfilenfermagem/ pdfs/relatoriofinal.pdf

2. Machado MH, Aguiar Filho W, Lacerda WF, Oliveira E, Lemos W, Wermelinger M, et al. Características gerais da enfermagem: o perfil sociodemográfico. Enferm Foco [Internet]. 2016 [acesso em 2020 jun 21]; 7. Disponível em: https://doi.org/10.21675/2357-707X.2016.v7.nESP.686

3. Caetano AS, Prado JTC. Mercado de trabalho: condições gerais do trabalho da enfermagem. Divulg Saúde Debate. 2016; 56:98-105.

4. Barbosa TLA, Gomes LMX, Reis TC, Leite MTS. Expectativas e percepções dos estudantes do curso técnico em enfermagem com relação ao mercado de trabalho. Texto Contexto Enferm [Internet]. 2011 [acesso em 2020 mar 02]; 20. Disponível em: https://doi.org/10.1590/S0104-07072011000500005

5. Andrade MV, Coelho AQ, Xavier Neto M, Carvalho LR, Atun R, Castro MC. Transition to universal primary health care coverage in Brazil: Analysis of uptake and expansion patterns of Brazil's Family Health Strategy (1998-2012). PLoS One [Internet]. 2018 [acesso em 2020 mar 05]; 13(8): e0201723. Disponível em: https:// doi.org/10.1371/journal.pone.0201723

6. Ximenes-Neto FRG, Lopes Neto D, Cunha ICKO, Ribeiro MA, Freire NP, Kalinowski CE, et al. Reflexões sobre a formação em Enfermagem no Brasil a partir da regulamentação do Sistema Único de Saúde. Ciênc Saúde Colet [Internet]. 2020 [acesso em 2020 mar 08]; 25(1). Disponível em: https://doi.org/10.1590/141381232020251.27702019

7. Lima A, Lopes LCS, Soane AMNC, Fortes AFA. Egressos de enfermagem: potencialidades no processo de formação profissional para inserção no mercado de trabalho. Indagatio Didactica [Internet]. 2017 [acesso em 2020 mar 08]; 9(4). Disponível em: https://doi.org/10.34624/id.v9i4.715

8. Jesus BH, Gomes DC, Spillere LBB, Prado ML, Canever BP. Inserção no mercado de trabalho: trajetória de egressos de um curso de graduação em enfermagem. Esc Anna Nery [Internet]. 2013 [acesso em 2020 jun 04]; 17(2). Disponível em: https://doi.org/10.1590/S1414-81452013000200019

9. Mattia BJ, Kleba ME, Prado ML. Formação em enfermagem e a prática profissional: uma revisão integrativa da literatura. Rev Bras Enferm [Internet]. 2018 [acesso em 2020 jun 12]; 71(4). Disponível em: https://doi.org/10.1590/0034-7167-2016-0504

10. Püschel VAA, Costa D, Reis PP, Oliveira LB, Carbogim FC. Nurses in the labor market: professional insertion, competencies and skills. Rev Bras Enferm [Internet]. 2017 [acesso em 2020 mar 08]; 70(6). Disponível em: https://doi.org/10.1590/0034-7167-2016-0061

11. Barbosa ACS, Luiz FS, Friedrich DBC, Püschel VAA, Farah BF, Carbogim FC. Perfil de egressos de Enfermagem: competências e inserção profissional. Rev Lat-Amer Enferm [Internet]. 2019 [acesso em 2020 jun 21]; 27: e3205. Disponível em: https://doi.org/10.1590/1518-8345.3222.3205

12. Cambiriba TDC, Ferronato AF, Fontes KB. Percepções de egressos de enfermagem frente a inserção no mercado de trabalho. Arq Ciênc Saúde UNIPAR [Internet]. 2014 [acesso em 2020 jun 08]; 18(1). Disponível em: https://doi.org/10.25110/arqsaude.v18i1.2014.5155 
13. Oliveira JSA, Pires DEP, Alvarez AM, Sena RR, Medeiros SM, Andrade SR. Trends in the job market of nurses in theviewof managers. Rev Bras Enferm [Internet]. 2018 [acesso em 2020 mar 05]; 71(1). Disponível em: https://doi.org/10.1590/0034-7167-2016-0103

14. Colenci R, Berti HW. Formação profissional e inserção no mercado de trabalho: percepções de egressos de graduação em enfermagem. Rev Esc Enferm USP [Internet]. 2012 [acesso em 2020 mar 08]; 46(1). Disponível em: https://doi.org/10.1590/S0080-62342012000100022

15. Bardin L. Análise de conteúdo. 3 ed. São Paulo: Edições 70; 2016.

16. Souza NVDO, Penna LHG, Cunha LS, Mafra IF, Mariano DCA. Perfil socioeconômico e cultural do estudante ingressante no curso de graduação em enfermagem. Rev Enferm UERJ. 2013; 21(2):718-22.

17. Corrêa AK, Prebill GM, Ruiz JC, Souza MCBM, Santos RA. O perfil do aluno ingressante em um curso de bacharelado e licenciatura em enfermagem de uma instituição de ensino superior pública. Educ Rev [Internet]. 2018 [acesso em 2020 mar 08]; 34: e185913. Disponível em: https://doi.org/10.1590/01024698185913

18. Palazzo J, Gomes CA. Origens sociais dos futuros educadores: a democratização desigual da educação superior. Rev Aval Educ Sup [Internet]. 2012 [acesso em 2020 mar 02]; 17(3). Disponível em: https://doi. org/10.1590/S1414-40772012000300013

19. Silva TA. Identidade e escolhas profissionais na perspectiva de graduandos de enfermagem [Dissertação]. São Paulo, SP: Universidade de São Paulo; 2015.

20. Anderson JSN, Schneider S. Brazilian demographic transitionand the strategic role of youth. Espace Popul Soc [Internet]. 2015 [acesso em 2020 mar 05]; 2/3. Disponível em: https://doi.org/10.4000/eps.5774

21. Meira MDD, Kurcgant P. Nursing education: training evaluation by graduates, employers and teachers. Rev Bras Enferm [Internet]. 2016 [acesso em 2020 mar 02]; 69(1). Disponível em: https://doi. org/10.1590/0034-7167.2016690102i

22. Umpiérrez AHF, Merighi MAB, Muñoz LA. Percepções e expectativas dos enfermeiros sobre sua atuação profissional. Acta Paul Enferm [Internet]. 2013 [acesso em 2020 mar 04]; 26(2). Disponível em: https://doi.org/10.1590/S0103-21002013000200010

23. Leal LA, Soares MI, Silva BR, Bernardes A, Camelo SHH. Clinical and management skills for hospital nurses: perspective of nursing university students. Rev Bras Enferm [Internet]. 2018 [acesso em 2020 mar 03];71(Suppl 4). Disponível em: https://doi.org/10.1590/0034-7167-2017-0452

RECEBIDO: $22 / 08 / 2020$

ACEITO: $17 / 11 / 2020$ 